\title{
Limitação ao Uso Agrícola da Propriedade \\ RuRal Pela Instituição de Reserva Legal
}

Florestal

Carlos Cesar Ronquim*

Adhemar Ronquim Filho**

\section{Resumo}

O presente texto aborda as limitações de proteção especial dos recursos naturais nas propriedades agrícolas representadas pela Reserva Legal Florestal(RLF) a partir de sua origem, até a forma pela qual é tutelada atualmente. São estabelecidas as suas relações e diferenciações. Formas para as recomposições e utilização da RLF são abordadas. Por fim, são ressaltados os argumentos dos setores ambientalistas e ruralistas para o aperfeiçoamento do instituto e sua aplicabilidade, apresentando-se formas de ser posto em prática o almejado desenvolvimento sustentável.

Palavras Chave: Meio ambiente; Reserva Legal Florestal; Uso do solo agrícola.

\section{INTRODUÇão}

O acirramento do debate sobre a imposição da instituição da Reserva Legal Florestal (RLF) e de sua extensão nas propriedades, atualmente, coloca o tema na pauta principal de quaisquer debates a serem travados entre os ambientalistas mais acirrados e os integrantes do setor ruralista. Inclusive, o Congresso Nacional vem sendo alvo de grande mobilização por ambos os setores, pois neste momento se fala em alteração do Código Florestal e, por consequência, do regramento da RLF.

Independentemente dessa discussão, e do fato de que ambos os grupos possuem argumentos plausíveis e respeitáveis, este simples e rápido trabalho se preocupará apenas em traçar o quadro atual legal do instituto e de sua aplicação, bem como algumas propostas existentes de alteração da regulação da matéria. Formas de compensação são mencionadas, além de experiências existentes que representammeios

\footnotetext{
*Pesquisador, doutor em Ecologia da Embrapa Monitoramento por Satélite. Av. Soldado Passarinho, 303, CEP 13070-115, Campinas-SP. Fone: (19) 3211-6200. E-mail: ronquim@cnpm.embrapa.br.

**Advogado, professor universitário de Legislação Ambiental. Rua Floriano Peixoto, n. ${ }^{\circ}$ 616, Centro, CEP 14815-000, Ibaté-SP. Fone: (16) 3343-1299. E-mail: aronquim@ gmail.com.
} 
que possam, ao mesmo tempo, cumprir a norma, preservar o meio ambiente e não onerar demais os proprietários.

A intenção é contribuir para o debate, sem pacificar nenhuma opinião, respeitando ambas as partes, sempre com vistas a aplicar a lição do historiador Alexandre Herculano, "eu não me envergonho de corrigir os meus erros e mudar de opinião, porque não me envergonho de raciocinar e aprender".

\section{LIMITAÇÃo À UTILIZAÇÃo DA PROPRIEDADE RURAL}

O Direito Ambiental não se insere na esfera do Direito Público (que rege a relação entre o Estado e os particulares) e, muito menos, tem caráter de Direito Privado (regência da relação entre particulares). Tem, sim, o cunho de Direito Difuso, o qual pertence aos Direitos de Terceira Geração, e é representado pelos Direitos Ambiental, do Consumidor, da Infância e da Juventude, dentre outros. Direitos Difusos são aqueles cujo bem tutelado não é particular, não é público, mas de todos, ou, tecnicamente descrevendo, pertence a uma coletividade indeterminável e com cunho indivisível, ou seja, é global, não podendo ser dividido em favor dos titulares.

A Constituição Federal (CF) de 1988 trouxe-nos, com precisão, o meio ambiente como bem difuso, ao exprimir no artigo 225 :

Todos têm direito ao meio ambiente ecologicamente equilibrado, bem de uso comum do povo e essencial à sadia qualidade de vida, impondose ao Poder Público e à coletividade o dever de defendê-lo e preserválo para as presentes e futuras gerações.

Para a CF/1988, a propriedade é um direito individual e/ou coletivo, sendo garantido desde que atenda a sua função social e, desta feita, pode ser objeto de restrições, como fonte de Justiça social.

É expresso na $C F / 1988$ que a função social da propriedade rural apenas é cumprida quando, dentre outros requisitos, há uma utilização sustentável dos recursos naturais disponíveis e a preservação ao meio ambiente, escancarando, portanto, a denominada função ambiental da propriedade.

Todo esse conjunto de definições, princípios e instrumentos tratados acima tem o condão de subsidiar a limitação à propriedade particular, manifestada pela instituição da RLF. Esta tem fundamento no uso sustentável dos recursos naturais de interesse difuso, ou seja, se relaciona a toda uma coletividade indeterminávele, portanto, as vontades individuais podem ser suprimidas a fim de que o bem privado cumpra a sua função ambiental, necessária ao futuro da humanidade.

Todo esse histórico justifica o porquê da admissibilidade da intervenção na 
propriedade privada, a fim de que seja preservado o meio ambiente, por ser este um bem irrenunciável, pertencente a todos, devendo ser defendido com vigor, havendo, neste caso, uma concessão do bem individual em favor da coletividade.

\section{A ReSERVA Legal Florestal e a PROTEÇão AMbIENTAL NA PROPRIEDADE AGRícola}

Aidéia de RLF foi introduzida no primeiro Código Florestal, de 1934 (revogado), que impedia os proprietários de terras, possuidoras de matas, que abatessem mais de três quartas partes da vegetação existente. A criação originária da RLF obstinou, em áreas colonizadas há tempos, e também ocupadas com desmatamento elevado, em garantir um mínimo de recursos florestais para a utilização na propriedade e no mercado de carvão, lenha e madeira. No entanto, o termo passou a ser sinônimo da restrição à utilização da propriedade para a preservação do meio ambiente, quando trazido pela Lei n. $.^{\circ} 7.803 / 1989$, que alterou o Código Florestal de 1965, fixando em seu artigo $16, \S 2 .^{\circ}$ :

"A reserva legal, assim entendida a área de, no mínimo, 20\% (vinte por cento) de cada propriedade, onde não é permitido o corte raso, deverá ser averbada à margem da inscrição de matrícula do imóvel, no registro de imóveis competente, sendo vedada, a alteração de sua destinação, nos casos de transmissão, a qualquer título, ou de desmembramento da área."

No entanto, o artigo 16 do Código Florestal foi alterado novamente e ganhou a atual redação com a edição da Medida Provisória (MPV) n. ${ }^{\circ}$ 2.166-67, de 24/08/ 2001, que redefiniu integralmente este dispositivo legal.

Além de definir expressamente o conceito de RLF, a MPV n. ${ }^{\circ}$ 2.166-67 trouxe os limites mínimos a ser aplicados em cada propriedade, todos no artigo 16 e seus incisos do Código Florestal, sendo de $80 \%$ (oitenta porcento) em propriedade rural situada na Amazônia Legal; 35\% (trinta e cinco porcento) na propriedade rural situada em área de Cerrado localizada na Amazônia Legal - no mínimo 20\% na propriedade e $15 \%$ na forma de compensação em outra área, desde que esteja localizada na mesma microbacia -; $20 \%$ (vinte porcento) na propriedade rural situada em área de floresta, ou outras formas de vegetação nativa, localizada nas demais regiões do país; e $20 \%$ (vinte por cento) na propriedade rural emárea de campos gerais localizada em qualquer região do país.

Como se vê, para cada região foi determinado um percentual mínimo fixado a título de RLF, sendo que, para áreas situadas na Amazônia Legal, a restrição chega a, no mínimo, 4/5 (quatro quintos) do imóvel, preocupação consequente das elevadas taxas 
de desmatamento apuradas na década de 90 (o máximo de desmatamento foi de 29,1 mil km², no ano de 1995), em decorrência da exploração acelerada da Região Amazônica, o que forçou o legislador brasileiro a aumentar os percentuais de RLF na área.

A MPV n..$^{\circ}$ 2.166-67, até a data de hoje, não foi convertida em lei e, dessa forma, atualmente a RLF tem a sua redação e é aplicada com base em um ato normativo supostamente temporário, pois as MPVs, de regra, anteriores a 2001, continuam em vigor até que Medida Provisória ulterior as revogue explicitamente ou até deliberação definitiva do Congresso Nacional ${ }^{1}$. No caso da MPV n. ${ }^{\circ}$ 2.166-67, nenhuma das possibilidades citadas ocorreu, o que nos leva a refletir se não manter-se-á tacitamente permanente, sendo uma aberração jurídica contra a qual não há expediente, pois fundada na própria Carta Magna.

Apesar de a averbação da RLF nas propriedades agrícolas ser obrigatória desde 1989 (Lei Agrícola n. ${ }^{\circ} 8.171$, de 1991), muitos produtores se negam a realizá-la, pois, a partir daquele momento, a área se tornar permanentemente destinada à preservação. Além disso, acreditam muitos proprietários que as novas metragens de RLF impostas pela Medida Provisória n. ${ }^{\circ}$ 2.166-67 possam ser alteradas pelo Congresso Nacional, ou até mesmo revogadas e, desta feita, temem destinar uma parcela expressiva de sua propriedade rural à preservação e não poder alterar o uso dessa terra, caso ocorram mudanças na lei. A única conclusão que se pode ter é que, até que seja regulada a MPV no 2.166-67, se for, tem esta aplicabilidade na regulamentação na temática da RLF, pois àquela se acaba por atribuir um efeito de lei, sendo imperativa.

A lei permite que as Áreas de Preservação Permanente (APPs) sejam consideradas como parte da RLF em alguns casos. É atribuição do órgão ambiental competente acatar que o proprietário compute áreas de vegetação nativa, situadas em APPs, no cálculo da RLF, desde que: a soma da vegetação nativa em área de preservação permanente e reserva legal exceder a: I-80\% (oitenta porcento) da propriedade rural localizada na Amazônia Legal; II - 50\% (cinquenta porcento) da propriedade rural localizada nas demais regiões do país; e III - 25\% (vinte e cinco porcento) da pequena propriedade definida pelas alíneas "b" e "c" do inciso I do $\S 2 .^{\circ}$ o do art. 1. ${ }^{\circ}$ (art. 16, $\S$ 6. ${ }^{\circ}$, do Código Florestal).

O que se pode concluir é que, à exceção de áreas situadas na Amazônia Legal e em pequenas propriedades, que possuem percentuais próprios, em regra geral, nas grandes

\footnotetext{
${ }^{1}$ Saliente-se que as MPVs que foram editadas anteriormente à Emenda Constitucional (EC) n. ${ }^{\text {o } 32 / 2001}$ terão vigor até que, eventualmente, haja a sua revogação ou a expressa manifestação do Poder Legislativo sobre a mesma, podendo convertê-la em lei ordinária ou não. Até que ocorra qualquer das possibilidades citadas, estas MPVs terão vida eterna e plena aplicabilidade.
} 
áreas das demais regiões do país, a RLF dependerá, necessariamente, da extensão de APP. Emoutras palavras, se esta estiver ocupando menos de $50 \%$ (cinquenta porcento) de uma dada propriedade, a área a ser averbada de RLF corresponderá à porcentagem restante para se atingir o mínimo de vegetação nativa, estatuído no artigo $16, \S 6^{\circ}$, II, do Código Florestal.

No Estado de São Paulo, se a APP representar até $30 \%$ da área da propriedade, a RL será de 20\%; no entanto, se a APP possuir entre $30 \%$ e $50 \%$ da área da propriedade, a RL será de $50 \%$ da área da APP; e, por fim, se a APP representar mais de 50\% da área da propriedade, não há a necessidade de averbação de RL.

Na esfera nacional, encontra-se atualmente tramitando perante a Câmara dos Deputados em Brasília-DF, o Projeto de Lei (PL) n. ${ }^{\circ}$ 6.424/2005, que possui em seu bojo possíveis alterações no Código Florestal, destacando-se modificações nas regras da RLF, bem como em sua compensação. Talvez a mais polêmica alteração trazida pelo PLn. ${ }^{\circ}$ 6.424/2005 seria a possibilidade de compensação da APP no percentual da $\operatorname{RLF}^{2}$. Na prática, essa nova compreensão eliminará a RLF emalgumas regiões do país, sendo, portanto, a que vem carreando um maior número de controvérsias e discussões.

De fato, a compensação de APP com RLF há muito vem sendo almejada pelo setor ruralista, o qual vê, nesta possibilidade, um meio de equilíbrio para o desenvolvimento sustentável, ou seja, uma forma de preservar sem estrangular as atividades econômicas. Por outro lado, ambientalistas veem nisso um retrocesso sem precedentes em todos os ganhos ambientais conseguidos no Brasil, levando-seà extinção do instituto (RLF) em várias partes do país, sendo inócuo todo o trabalho realizado de manutenção arbórea, podendo ocasionar um prejuízo sem precedentes na luta brasileira que se trava há tempos na questão ambiental.

${ }^{2}$ A proposta de redação do artigo 16 , do Código Florestal, é a seguinte:

"Art. 16 (...)

$\S 12$. Será admitido, pelo órgão ambiental competente, o cômputo das áreas relativas à vegetação nativa existente em área de preservação permanente no cálculo do percentual de reserva legal, desde que não implique em conversão de novas áreas para o uso alternativo do solo e sejam observadas cumulativamente as seguintes condições:

a) o imóvel seja integrado ao cadastro ambiental georreferenciado previsto no artigo 44-D desta Lei no prazo máximo de três anos a partir de sua vigência;

b) o proprietário do imóvel em processo de regularização comprometa-se a recuperar a cobertura vegetal necessária para compor a Área de Preservação permanente - APP em até dez anos contados a partir da data do cadastramento do imóvel referido no inciso anterior, e completar o percentual de reserva legal em área contígua na própria propriedade; e

c) adoção de técnicas de manejo do solo para contenção de erosão e boas práticas agropecuárias estabelecidas pelo órgão estadual ambiental" (NR). 
A extinção da figura da RLFe o acréscimo de área nas APPs podem trazer vantagens ambientais, desde que essa nova configuração seja adequadamente planejada. Esta nova estrutura de preservação, formando corredores contínuos de vegetação, é mais adequada, do ponto de vista da conservação da biodiversidade, do que a criação de RLFs em fragmentos. A ampliação da área de APP e a eliminação da RLF foram testadas por Rossener \& Ranieri (2008), na região de Ribeirão Preto-SP. Eles observaram que, se a faixa de APP for aumentada de 30 para 180 metros, com a manutenção de alguns fragmentos de vegetação nativa existentes, a área total de vegetação nativa a ser conservada se aproxima da exigida pela norma brasileira. Em outro estudo, na Região Amazônica, Less \& Peres (2008) observaram que, quanto maiores e mais preservados os corredores formados pelas APPs, maiores são as quantidade e riqueza de espécies animais, comprovando-se que os corredores florestais são os principais instrumentos para se combater a perda de habitats e a fragmentação. Os mesmos autores sugerem, ainda, uma revisão do Código Florestal, a fim de que as APPs passema ter, no mínimo, 200 (duzentos) metros para cada lado de qualquer curso d'água, especialmente daqueles superiores a 10 (dez) metros de largura.

A dicotomia entre os ruralistas e os ambientalistas vem se acirrando cada vez mais, o que enseja, ante a eventual aprovação do PL n. ${ }^{\circ}$ 6.424/2005, a realização de inúmeras Audiências Públicas e o estímulo de meios para a participação da sociedade civil em geral neste debate, o que é deveras aconselhável, tendo em vista que se trata da destinação futura do instituto da RLF, e o que se deve ser respondido é a possibilidade ou não de sua amenização, nos termos propostos pelo PL n. ${ }^{\circ}$ 6.424/2005.

\section{Recomposição E UTILIZaÇão da Reserva Legal Florestal Na PROPRIEdAde AGRíCOLA}

A Lei n. ${ }^{\circ}$ 8.171/1991, que dispõe sobre a Política Agrícola, estabelece a obrigatoriedade de recomposição vegetal das propriedades rurais por meio de reflorestamento com espécies nativas. Ela determina ao proprietário rural, que não tenha a totalidade ou a parcela da RLF definida em lei, sua recomposição, com a plantação, a cada três anos, de espécies nativas, em, no mínimo, 1/10 (um décimo) da área total necessária a sua complementação, sempre sob a supervisão e o assentimento do órgão ambiental estadual competente. Além disso, a Lei Agrícola reconhece, de modo inequívoco, a obrigação do proprietário de recompor a RL de sua propriedade.

Por ser a proteção ao meio ambiente um dever de todos, direciona a lei, ao particular, a obrigação das regeneração e/ou recomposição da área a ser delimitada como de RLF às suas expensas, em benefício da coletividade. Como já realçado, no entanto, o legislador, ciente das dificuldades que, eventualmente, poderão ser advindas ao proprietário por este encargo, disponibilizou opções e prazos para as 
recomposição e/ou regeneração.

A legislação determina que a localização da RLF tem de ser aprovada pelo órgão ambiental estadual competente. A aprovação tem de levar em conta vários aspectos, como o Plano de Bacia Hidrográfica, o Plano Diretor Municipal, a proximidade com outra área de APP, dentre outros.

Em área de RLF, a utilização deve ter relação com o regime de manejo florestal sustentável, sendo vedado o corte raso, o qual se trata de ilícito administrativo. Por força do Decreto n. ${ }^{\circ}$ 5.975/2006, houve a regulamentação do Plano de Manejo Florestal Sustentável (PMFS), de aplicação nacional, documento que estabelece moldes para a administração das florestas, com a obtenção de benefícios sociais, ambientais e econômicos, estando isento de submeter a este programa o manejo de florestas plantadas localizadas fora das áreas de RLF.

O decreto citado apenas permitiu a exploração de florestas, e a supressão de vegetação arbórea, mediante autorização do órgão competente do Sistema Nacional do Meio Ambiente (Sisnama). Para o requerimento de autorização de supressão, deverá o proprietário e/ou possuidor fornecer, no mínimo, informações como a localização georreferenciada do imóvel, contendo a área de RLF; a demonstração de qual será o uso alternativo do solo que será desmatado; dentre outras.

Em benefício da pequena propriedade ou posse rural familiar (explorada mediante o trabalho pessoal do proprietário, ou posseiro, e de sua família, e cuja renda bruta seja proveniente, no mínimo, em $80 \%$ - oitenta porcento - de atividade agroflorestal ou do extrativismo, respeitando-se um certo limite de área, em hectares, diferente para cada região do país), na manutenção da área de RLF, pode computar-se os plantios de árvores frutíferas ornamentais ou industriais, incluindo espécies exóticas, admitindose, também, o consórcio com espécies nativas. Outra vantagem, assegurada ao pequeno proprietário rural ou possuidor familiar, é a dispensa das indicações georreferenciadas

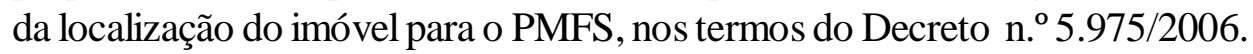

Essa flexibilização visa dar base e melhores possibilidades aos que possuem menores condições financeiras, detentores de pequena propriedade rural, buscando criar a lei artifícios favoráveis que possam auxiliá-los no cumprimento da obrigação legal. O único inconveniente é que os benefícios trazidos pela lei poderão eliminar a RLF em áreas nas quais exista a predominância de pequenas propriedades rurais, enfraquecendo a preservação ambiental.

Englobando as propriedades rurais de qualquer tamanho, no Estado de São Paulo foi editada a Lei n. ${ }^{\circ}$ 12.927/2008, que se ocupou, principalmente, em estabelecer diretrizes para, como forma de compensação de RL, ser admitida a plantação de espécies arbóreas exóticas, para atender aos fins do instituto e à manutenção saudável do meio ambiente. Saliente-se que esta unidade da federação tem, segundo dados da 
própria administração, das 230 mil propriedades rurais existentes em seu território, apenas 30 mil com RLFestabelecida com os $20 \%$ (vinte porcento) mínimos exigidos pelo Código Florestal.

Com isso, são admitidas, para o cômputo de espécies arbóreas, tanto as nativas quanto as exóticas ao ecossistema do lugar, como forma de favorecer ao detentor da área, o qual, além disso, pode explorá-la, desde que se utilizando de um manejo sustentável. O proprietário ou o titular da exploração do imóvel deverá implantar o sistema no prazo máximo de oito anos, utilizando no máximo 50\% de espécies arbóreas exóticas, caso opte pela recomposição da RLF nestes termos, não podendo haver o replantio de espécies arbóreas exóticas na RLF, findo o ciclo de produção do plantio inicial, exceto no caso de pequenas propriedades.

Apesar de a Lei n. $^{\circ}$ 12.927/2008 parecer ambientalmente incorreta, deve-se salientar que diversos trabalhos científicos vêm demonstrando maior desempenho de algumas espécies nativas desenvolvendo-se no sub-bosque de espécies arbóreas exóticas do que em condições de áreas abertas (LUGO, 1997; DURIGAN, 2004; Brocherhoff et al., 2008). O aumento da complexidade estrutural e a grande variedade de espécies florestais nativas lenhosas, que surgem sob o dossel, devem-se a mudanças nas condições microclimáticas, menor competição com gramíneas e melhorias físicas, químicas e biológicas do solo. Salienta-se que as plantas consideradas "espécies exóticas-problema", ou seja, aquelas as quais poderão interferir negativamente no desenvolvimento da recuperação florestal, como a Leucaena spp, dentre outras, estão vetadas no Estado de São Paulo.

Essa política da consorciação de espécies nativas e exóticas concilia a produção com a conservação ambiental, e pode incentivar os proprietários agrícolas a revegetar suas áreas de RLF, pois, com a posterior comercialização madeireira ou outros subprodutos das espécies exóticas, podem ser gerados lucros para a propriedade ou mesmo ser cobertos os custos com a implantação da RLF. Autilização de espécies exóticas deve ser vista como uma etapa intermediária, para que, no futuro, se tenha uma floresta diversificada, composta somente por espécies nativas regionais.

Aproveitando a menção às espécies exóticas, o PL n. ${ }^{\circ}$ 6.424/2005, atualmente tramitando na Câmara dos Deputados em Brasília-DF, propõe que $30 \%$ das RLFs da Amazônia possam ser mantidas com espécies comerciais perenes nativas ou exóticas ao ecossistema do lugar e, por consequência, nelas seja desenvolvida atividade econômica, especialmente o cultivo de matéria-prima para a produção de biocombustíveis, mantendo-se intactas, na região, apenas $50 \%$ das propriedades.

O PLn. ${ }^{\circ}$ 6.424/2005 é atacado por ambientalistas por ser a exploração de espécies comerciais exóticas um fim, e não uma etapa intermediária, a qual proporcionaria o repovoamento da área com espécies nativas naturais desse ecossistema. Por outro 
lado, os ruralistas acrescentam que essa seria uma possibilidade viável economicamente para recuperar as áreas já degradadas, e daria ao proprietário rural mais uma opção para a recomposição florestal a que está obrigado por lei, gerando renda e empregos na Região Amazônica.

\section{A RESTRIÇÃo AMbiental LEgal da PROPRIEDAde RURAL POR PARTE DA RLF E SEUS INTERMINÁVEIS DEBATES}

A RLF é alvejada de críticas por parte, principalmente, do setor ruralista, que possui a necessidade da plena extensão de sua propriedade para o desenvolvimento de suas atividades econômicas. O impacto desfavorável que é imposto à economia agrícola, defendemos ruralistas, é excessivo, havendo um desequilíbrio que sufoca o setor, em que pese ser indiscutível que o meio ambiente saudável é precioso e não pode ser renunciado.

De acordo com o grupo dos ruralistas, a RLF, criação genuína e exclusivamente brasileira, não atende aos fins de sua proposição, e a sua imposição generalista, sem a legislação ater-se às peculiaridades de cada Estado ou região, ou à vocação econômica da área, atravanca as atividades de produção. Além disso, não atingiria os seus objetivos, pois os proprietários, na maioria das vezes, não conseguem fazer a recomposição da área, e, posteriormente, a fixação da RLF, por motivos operacionais e até econômicos.

Em estudo feito por Bacha (2005), na região de Piracicaba-SP, a taxa interna de retorno da cultura de cana-de-açúcar em 2004 seria reduzida para 28,84\% com a incorporação da RLF dentro da propriedade, contra 37,23\% sem a RLF. O trabalho mostra que, nesses casos, a saída mais razoável parece ser a criação da RLF em área externa à propriedade comercial, em terras de pastagens, por exemplo, nas quais o custo de oportunidade é menor, gerando uma taxa de retorno de $32,85 \%$. Já Titton (2007) afirma que, se os proprietários rurais paulistas deixarem de explorar uma parte da sua propriedade para a implantação da RLF, reduzindo sua fonte de renda, poderá ocorrer uma redução de $17 \%$ da área rural atualmente destinada à produção e consequente queda de 5\% (cinco porcento) no PIB do Estado de São Paulo, além da perda de $6 \%$ no repasse do ICMS aos municípios. No caso do Estado do Paraná, Padilha Jr. (2004) apurou que o prejuízo econômico total da RLF sobre a agropecuária atingiu, na época da pesquisa, valores próximos a $\mathrm{R} \$ 90$ bilhões, no mínimo, sem contar custos com averbação, topografia, dentre outros, o que aumentaria, em muito, estas cifras, o que subsidia verificar não ser absurdas as postulações da classe agrícola.

Outro consenso entre os ruralistas, principalmente no que se refere às propriedades de pequeno porte, é em relação à funcionalidade dos pequenos fragmentos da RLF em suas áreas, alegando que a preservação da biodiversidade só é possível em grandes áreas, ao passo que, em pequenas extensões ou áreas isoladas, não se consegue 
formar corredores ecológicos. Isso é uma verdade, pois fragmentos pequenos são basicamente bordas na sua totalidade, não tendo nenhum ambiente de interior de mata.

Há prejuízos, portanto, tanto à fauna quanto à flora, na medida em que animais de interior não têm o seu habitat e fogem ou são extintos localmente, e plantas sofrem com as alterações das condições fisiológicas e climáticas, além de perder seus polinizadores e dispersores. O resultado é o colapso dessas florestas e a continuada perda da biodiversidade local.

A justificativa da manutenção desses pequenos fragmentos, principalmente no Estado de São Paulo, é a constatação de que a maior parte da biodiversidade se encontra hoje localizada neles (VIANA e PINHEIRO, 1998). De acordo com Rodrigues \& Bononi (2008), dos 3,5 milhões de hectares de vegetação remanescente no Estado de São Paulo, apenas 760 mil estão em unidades de conservação. O restante está em propriedades agrícolas particulares, e, para conservá-lo, é essencial transformar essas áreas em RLF.

Realmente, tem de haver um meio termo entre a preservação ambiental e a produção, sob pena de uma anular a outra e o conceito de desenvolvimento sustentável sucumbir, não apresentando efetividade prática e, sim, tratar-se de uma utópica e inviável meta. Ambas têm de conviver de formas correlata e harmônica para o êxito do instituto, das partes envolvidas e, enfim, do meio ambiente, pois se adota a visão antropocêntrica deste, não podendo ser, semqualquer razão, umentrave ao desenvolvimento econômico, o qual, por sua vez, não pode, também, ser o predador do meio ambiente saudável, sob pena de vitimar futuras gerações. Enfim, tem de ser estimuladas formas para que essas questões ambientais e econômicas possam viver harmonicamente, com bons frutos para os dois lados.

É necessária, também, para o êxito pleno do instituto da RLF, a formação de áreas contínuas de florestas, com a constituição de corredores ecológicos, e não a sua existência de forma fragmentada, o que pode não evitar os impactos ambientais que se tenta combater com a instituição da RLF, colaborando para que seja inócua a sua averbação nas propriedades. Há de ser estimulados os zoneamentos econômicoecológicos, a fim de que, de acordo com a região, mesmo dentro da mesma subárea, sejam estipulados percentuais distintos de RLF, ou seja, obrigações maiores e/ou menores de instituição daquela, de acordo, também, como nível de atividade econômica que é realizada na área.

Exemplo de zoneamento econômico-ecológico foi dado pela Secretaria do Meio Ambiente do Estado de São Paulo, que apresentou uma resolução, em 2008, determinando os critérios para a autorização de supressão de vegetação nativa. Essa resolução estabeleceu um mapa, denominado "Áreas Prioritárias para Incremento para Conectividade", no qual são identificados os fragmentos considerados prioritários 
para conservação. Essas áreas passam a ser indicadas para a compensação da RLF das propriedades agrícolas, além de recomendar a interligação desses fragmentos, pela restauração da mata ciliar, funcionando como corredor ecológico.

\section{Conclusão}

Há muito o que se caminhar e o que se alterar no que pertine à RLF, o que pode apenas ser direcionado com o diálogo entre os setores interessados e envolvidos, respeitando-se os posicionamentos e os argumentos defendidos por ambas as partes. Independentemente disso, para as propostas não se tornarem inócuas - pois impossíveis de serem cumpridas por aqueles para quem se dirigem - ou tiranas - pois, em casos, se revelam severas e intransigentes demais -, é preciso que todas as mudanças e/ou atualizações devam ser analisadas com esmero, para se atingir os fins do instituto.

Portanto, o diálogo, neste caso, terá a função de manter o instituto da RLF. Os proprietários rurais e os ambientalistas têm fundamentos em suas reivindicações, e devem ser respeitados mutuamente, para a construção de uma RLF que, de fato, atenda ao que denominamos de desenvolvimento sustentável. Imparcialidade e cautela na solução dessa pendência é o que se pede por ora, não se esquecendo jamais de que é fundamental a preservação ambiental, apenas se podendo pactuar uma flexibilização ou não.

\section{REFERÊNCIAS}

BACHA, C. J. C. Eficácia da política de reserva legal no Brasil. Teoria e Evidência Econômica, Passo Fundo, v. 13, n. 25, nov. 2005.

BROCKERHOFF, E.G., JACTEL, H., PARROTTA, J.A., QUINE, C.P., SAYER, J. Plantation forests and biodiversity: oxymoron or opportunity? Biodiversity and Conservation 17, 925-951, 2008.

DURIGAN, G.; MELO, A. C. G.; CONTIERI, W. A.; NAKATA, H. Regeneração natural da vegetação de cerrado sob florestas plantadas com espécies nativas e exóticas. In: BOAS, O. V.; DURIGAN, G. Pesquisas em conservação e recuperação ambiental no Oeste Paulista: resultados da cooperação Brasil/ Japão. São Paulo: Páginas e Letras, 2004. p. 349-362.

LESS, A. C.; PERES C. A. Conservation value of remnant riparian forest corridors of varying quality for Amazonian birds and mammals. Conservation Biology, v. 22, n. 2, p. 439-449, 2008. 
LUGO, A. E. The apparent paradox of reestablishing species richness on degraded lands with tree monocultures. Forest Ecology and Management, n. 99, p. 9-19, 1997.

\section{PADILHA JÚNIOR, J. B. O Impacto da Reserva Legal Florestal sobre a} Agropecuária Paranaense, em um Ambiente de Risco. 181. Tese (Doutorado em Ciências Florestais) - Universidade Federal do Paraná, Curitiba, 2004.

ROSSENER, R. R. S.; RANIERI, V. E. L. Influência da ampliação das faixas de preservação permanente sobre a estrutura da paisagem: estudo exploratório na região de Ribeirão Preto (SP) utilizando ferramentas de geoprocessamento.

Minerva, v. 4, n. 1, p. 65-73, 2008.

RODRIGUES, R. R.; BONONI; V. L.R. (org.). Diretrizes para conservação e restauração da biodiversidade no Estado de São Paulo. São Paulo: Instituto de Botânica, 2008. 248 p.

TITTON, L. A. Reserva Legal: perdas e danos para a economia. Revista Canavieiros, v. 1, n. 18, p. 5-7, 2007.

VIANA, V. M.; PINHEIRO, L. A. F. V. Conservação da biodiversidade em fragmentos florestais. Piracicaba: IPEF, 1998. p. 25-42. (Série Técnica, 32).

Title: Limitation for the Agricultural Uses of the RuRal Properties REPRESENTED BY LFR (LEGAL FOREST RESERVES)

\section{Abstract}

The present text approaches the limitations of special protection of natural resources in the agricultural properties represented by Legal Forest Reserves (LFR), from their origin to the form they are being tutored now. Their relationships and differentiations are established. Forms for the recompositions and use of LFR are approached. Finally, the arguments of the environmentalists and ruralists are pointed out for the improvement of the institute and its applicability, presenting forms of putting in practice the desirable sustainable development

Keywords: Environment; Legal Forest Reserves; Agricultural soil use. 